\title{
An Experimental Determination of Temperature Profile in an Offset-halves Journal Bearing with Different Oils
}

\author{
Amit Chauhan $^{1)^{*}}$ and Rakesh Sehgal ${ }^{2)}$ \\ ${ }^{1)}$ Department of Mechanical Engineering, Panjab University Regional Centre \\ Bajwara, Hoshiarpur-146001 (Pb.), India \\ ${ }^{2)}$ Department of Mechanical Engineering, NIT \\ Hamirpur-177005 (H. P.), India \\ *Corresponding author: rsehgal@nitham.ac.in
}

( Manuscript received 21 June 2007; accepted 6 August 2007; published 31 August 2007 )

\begin{abstract}
In the present work, an offset-halves journal bearing with $I D=65 \mathrm{~mm}, O D=85 \mathrm{~mm}, L=65 \mathrm{~mm}, C m=200 \mu \mathrm{m}$ and $C=500 \mu \mathrm{m}$ has been tested to access temperature rise while operating with oils namely, Mak 2T, Hydrol 68 and Mak Multigrade at loads varying from 100-600 N and speeds from 3000-4000 rpm at constant supply pressure. Flow rates for different conditions were measured directly and the temperature information on three circumferential planes across the width of bearing was collected. The results indicate that with increase in load at constant speed and with increase in speed at constant load, the circumferential temperature of bearing increases in both the lobes for all the oils. For lower lobe, maximum temperature rise in central plane of the bearing is observed as $31.4^{\circ} \mathrm{C}$ for Mak Multigrade oil at $4000 \mathrm{rpm}$ and $600 \mathrm{~N}$ and minimum temperature rise is observed as $20.9^{\circ} \mathrm{C}$ for Mak $2 \mathrm{~T}$ oil at $3000 \mathrm{rpm}$ and $100 \mathrm{~N}$. For upper lobe, maximum temperature rise in central plane of the bearing is found to be $16.8^{\circ} \mathrm{C}$ for Mak Multigrade oil at $4000 \mathrm{rpm}$ and $600 \mathrm{~N}$ and minimum temperature rise is found to be $9^{\circ} \mathrm{C}$ for Mak $2 \mathrm{~T}$ oil at $3000 \mathrm{rpm}$ and $100 \mathrm{~N}$. Across the width of bearing, temperature rise is highest for Mak Multigrade oil $\left(17.9^{\circ} \mathrm{C}\right.$ at $\left.4000 \mathrm{rpm}, 600 \mathrm{~N}\right)$ and is lowest for Mak $2 \mathrm{~T}$ oil $\left(8.3^{\circ} \mathrm{C}\right.$ at $\left.3000 \mathrm{rpm}, 100 \mathrm{~N}\right)$. Hence under the chosen operating conditions (load up to $600 \mathrm{~N}$ and speed up to $4000 \mathrm{rpm}$ ) and the oils, it is appropriate to use Mak 2T oil so as to make the bearing run cool.
\end{abstract}

Keywords: offset-halves bearing, circumferential temperature, viscosity, Hydrol 68, Mak 2T, Mak Multigrade oil

\section{Introduction}

Journal bearings find applications mainly with high horsepower and high load machinery, such as steam turbines, centrifugal compressors, pumps and motors, which utilize journal bearings as rotor supports. One of basic purposes of a bearing is to provide a frictionless environment to support and guide a rotating shaft. The journal bearings operate under hydrodynamic lubrication regime. In this regime, a thick film of lubricant separates the surfaces. The separation of surfaces at load is as a result of pressure generation in fluid film. The combined effect of hydrodynamic action (relative velocities between journal and bush) and fluid film results in pressure generation. The load carrying capacity of fluid film depends upon the pressure generated within it. Under normal operating conditions, hydrodynamic plain journal bearings usually experience a considerable variation in temperature due to viscous dissipation. This can significantly affect the bearing performance since lubricant viscosity is strongly dependent on temperature. Moreover, excessive temperature can cause melting of the soft whitemetal liner or oxidation of the lubricant and, consequently, lead to failure of the bearing. Hence, it is of great importance to know temperature distribution in bearing, and can be, regarded as one of bearing design criteria.

Offset-halves bearings (Fig. 1) is commonly used as a lobed bearing in which two lobes are obtained by orthogonally displacing two halves of a cylindrical bearing and are frequently used in gear boxes connecting turbine and generator for power generation industries. These bearings find applications, when high bearing load capacity, long service life and high stiffness and damping values are the main criteria. The importance of thermal effects in hydrodynamic journal bearings has been recognized since long. Numerous investigations have been carried out both experimentally and theoretically by many researchers especially for circular and axial groove bearings. However, only a 


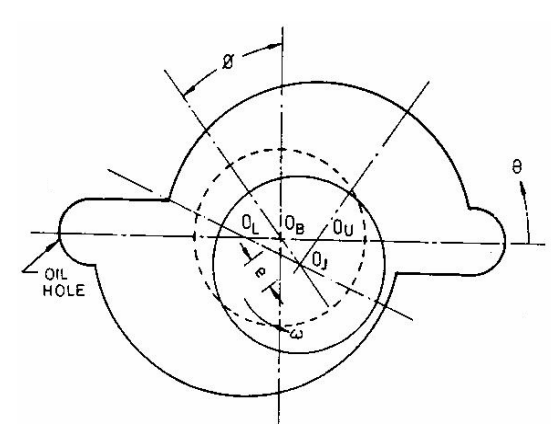

Fig. 1 Offset-halves journal bearing

limited experimental work has been reported for thermal effects in lobed bearing configurations such as offset-halves and elliptical/lemon bore bearings thus leading to the non availability of standard procedures for their design. Some recent experimental and theoretical work is reviewed here. An experimental investigation into large turbine bearings including an elliptical bearing and a tilting pad bearing of $500 \mathrm{~mm}$ journal diameter was reported by Hopf and Schuler ${ }^{1)}$ under transitional conditions between laminar and turbulent flow. It was found that under laminar flow conditions, circumferential temperature excursions and temperature differences across the film could be very significant. Read and Flack ${ }^{2)}$ established a test apparatus on which an offset-halves journal bearing of $70 \mathrm{~mm}$ diameter journal was tested. Fitzgerald and $\mathrm{Neal}^{3)}$ presented some experimental data for $76 \mathrm{~mm}$ diameter two-axial groove circular bearings. According to their results, axial temperature variation was negligible but circumferential temperature variation could be very significant. More recently, Basri and Gethin ${ }^{4)}$ completed some experiments for $75 \mathrm{~mm}$ diameter three-lobe profile bore bearings having symmetric tilted and side rail geometries under varying loading directions, and they found that thermal effects were significant in three lobe bearings. $\mathrm{Ma}$ and Taylor $^{5)}$ experimentally investigated the thermal behaviour of a two-axial-groove circular bearing and an elliptical bearing, both $110 \mathrm{~mm}$ in diameter, at specific loads upto $4 \mathrm{MPa}$ and rotational frequencies up to $120 \mathrm{~Hz}$. Power losses and flow rate were measured directly and detailed temperature information was collected. The results show that thermal effects are significant in both bearings. Sehgal et al. ${ }^{6}$ presented a comparative theoretical analysis of three types of hydrodynamic journal bearing profiles namely, circular, axial groove, and offset-halves. It was observed that offset bearing runs cooler than an equivalent circular bearing with axial grooves. Syverud $^{7)}$ experimentally investigated the surface temperatures and pressures in single bore journal bearings. Mishra et al. ${ }^{8)}$ considered non-circularity in bearing bore to be elliptical and made a comparison with circular one. It was observed that with increasing non-circularity, pressure gets reduced and temperature rise is less in case of bearing with high non-circularity.
The literature review reveals that almost all previous experimental work pertains to circular bearings. A very little was concerned with non-circular bearings especially the offset-halves journal bearings which are widely used in turbomachinery due to their excellent stability characteristics. In the present work, the thermal effects in an offset-halves bearing have been studied experimentally using three oils namely Mak 2T, Hydrol 68 and Mak Multigrade at different loads and varying speeds at constant supply pressure. The experiments were carried out on a specially designed journal bearing setup with provisions of direct flow rate measurement and temperature measurement on three circumferential planes of an offset-halves journal bearing. The experimental setup is described in the next section.

\section{Experimental setup}

The journal bearing test rig (Fig. 2) is designed to demonstrate difference in temperature at the middle and ends of offset-halves journal bearing by measuring its temperature at 22 different points, with provision to measure temperature at every 450 angular position on circumference of bearing (bush) which is made of Methyl Methacrylite. The journal made of C45 steel material is mounted horizontally on two pedestal bearings. The journal is rotated by a motor through $1: 2$ ratio pulleys, to attain speed up to $5700 \mathrm{rpm}$. A proximity sensor fixed on journal senses its speed. On circumference of bearing copper inserts are fixed on which 22 temperature sensors (RTD) are screwed to measure bearing circumferential temperature at 450 . In addition, one sensor is fixed to measure oil inlet temperature. A sleeve fits over journal and radial load is applied on bearing by 1:5 loading lever. Smaller end of the lever is hooked to the bearing by link and on bigger

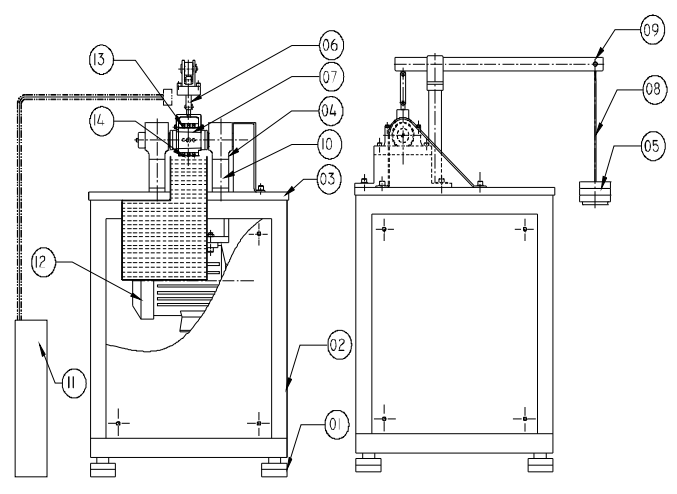

\begin{tabular}{|c|l|c|l|}
\hline Parts & Description & & \\
\hline 01 & Antivibration pad & 08 & Loading pan \\
\hline 02 & Structure & 09 & Lever \\
\hline 03 & Base plate & 10 & Timer belt \\
\hline 04 & Plummer block & 11 & Lube system \\
\hline 05 & Dead weight & 12 & Motor \\
\hline 06 & Lifting support lever & 13 & Test bearing \\
\hline 07 & Sleeve & 14 & Journal bearing \\
\hline
\end{tabular}

Fig. 2 Journal bearing test rig 
end a loading pan is suspended. Radial load is applied on bearing by placing dead weights on this loading pan. The test rig is designed to apply a maximum radial load up to $700 \mathrm{~N}$. Lubrication unit is made of a metallic tank with a motor and pump, by pass valve, control valve, pressure gauges, flow meter, inlet and delivery pipes. An oil sump is provided beneath the bearing for collecting used oil which flows into metallic tank for its re-circulation. Viscosity of oil is determined by FUNGILAB Digital Readout Viscometer Model "VISCOBASIC L". This viscometer model determines viscosity based on rotational principle that consists of spinning a submerged spindle in test material at a constant speed. The resistance generated by test material on this spindle is directly proportional to its viscosity. The instrument determines viscosity directly in digital form in Centi Poise (cP) in the range of 6-2000000 cP and rotational speed can vary from $0.3 \mathrm{rpm}$ to $100 \mathrm{rpm}$. Model is connected to JULABO Open Bath Circulator Model MP-5. Using open bath circulator (working temperature range $20-100^{\circ} \mathrm{C}$ ) the viscosity of the oil can be measured at desired temperature.

\section{Experimental programme}

An offset-halves bearing (Fig. 3) was tested using three oils namely Mak 2T, Hydrol 68 and Mak Multigrade at loads varying from 100-600 N, speeds varying from 3000-4000 rpm and constant supply pressure $\left(3 \mathrm{kgf} / \mathrm{cm}^{2}\right)$. The oil inlet temperature was $30^{\circ} \mathrm{C}$. The oil was supplied through two oil grooves at 900 to the vertical loading line. Tests were conducted for various combinations of the operating parameters.

\section{Results and discussion}

The variation of viscosity with temperature for three oils is plotted as Fig. 4. Experimentally obtained results for temperature are plotted as Figs. 5-16. Figs. 5-8 give temperature distribution of the bearing at oil-bush interface for Hydrol 68 oil corresponding to $3000 \mathrm{rpm}$, $4000 \mathrm{rpm}$ and at varying loads of $100 \mathrm{~N}$ and $600 \mathrm{~N}$. Figs. 9-12 give temperature distribution of the bearing at oil-bush interface for Mak 2T oil for the same set of journal speeds and loads. Similarly, Figs. 13-16 indicate the temperature distribution of bush-oil interface for journal speeds of $3000 \mathrm{rpm}, 4000 \mathrm{rpm}$ and at loads 100

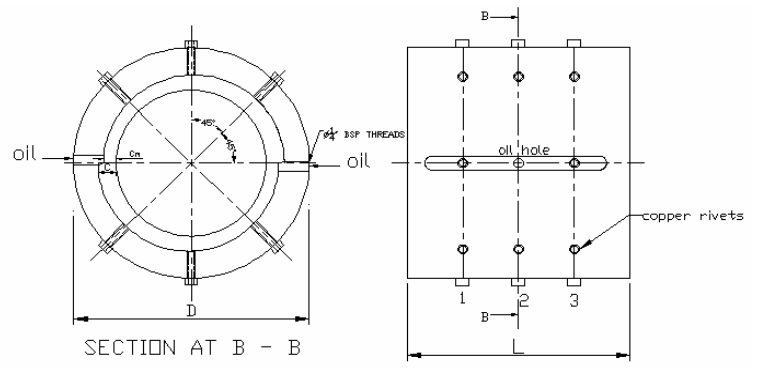

Fig. 3 Test offset-halves bearing

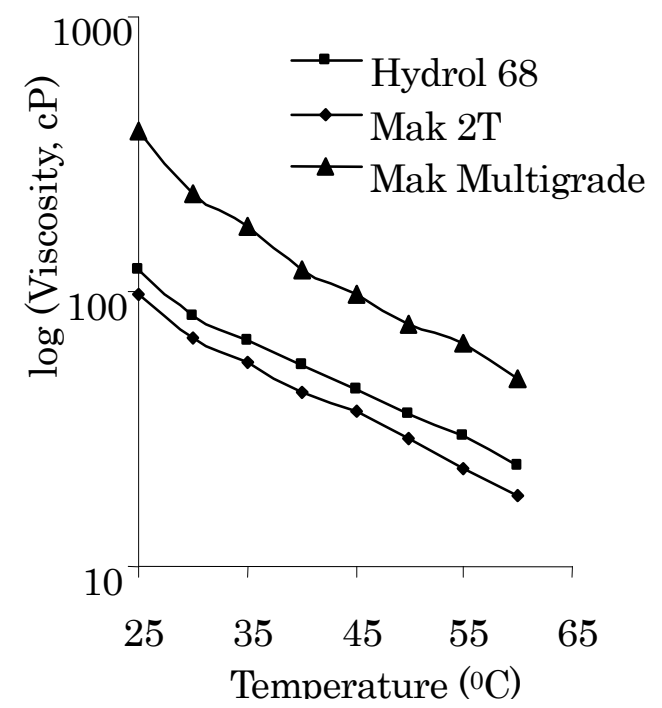

Fig. 4 Variation of viscosity with temperature for Hydrol 68, Mak 2T and Mak Multigrade Lubricating oil

$\mathrm{N}$ and $600 \mathrm{~N}$ for Mak Multigrade oil. From the data collected, it is observed;

1. increase in load at same speed and pressure, and with increase in speed at same load and pressure, temperature of bearing increases in both the lobes for all the oils. The temperature is high in central plane when compared with temperature on planes on either side of the central plane. Temperature rise is less at high loads. This can be attributed to increasing oil flow rate.

2. The temperature rise is least for Mak 2T oil. For low speeds, temperature rise is high for Mak Multigrade oil at low loads and temperature rise is high for Hydrol 68 oil at high loads. At high speeds, temperature rise is high for Mak Multigrade oil under all load conditions. Across the width of bearing, temperature rise is high at centre of the bearing for all oils and is highest for Mak Multigrade oil $\left(17.9^{\circ} \mathrm{C}\right.$ at $4000 \mathrm{rpm}, 600 \mathrm{~N}$, Fig. 16) and is lowest for Mak $2 \mathrm{~T}$ oil $\left(8.3^{\circ} \mathrm{C}\right.$ at $3000 \mathrm{rpm}, 100 \mathrm{~N}$, Fig. 9). This is probably due to fact that Mak Multigrade oil is highly viscous in nature which results in high frictional heat generation because of rubbing between oil layers.

3. Offset-halves bearing, because of its configuration, will have an active oil film in each lobe i.e. lower and upper lobe. Hence both lobes will have converging and diverging oil film zones (Fig. 1) which will lead to rise in oil temperature in both lobes (maximum temperature, being expected near the minimum film thickness in both lobes). It is observed during experimentation that as a result of loading (upward in lower lobe), maximum temperature rise is obtained near the point of minimum film thickness in lower lobe (shown in Figs. 5-16 as circle enclosed in an ellipse). The temperature rise is also obtained near the point of minimum film thickness in upper lobe (shown in Figs. 5-16 as circle) which 
For Hydrol 68 oil:

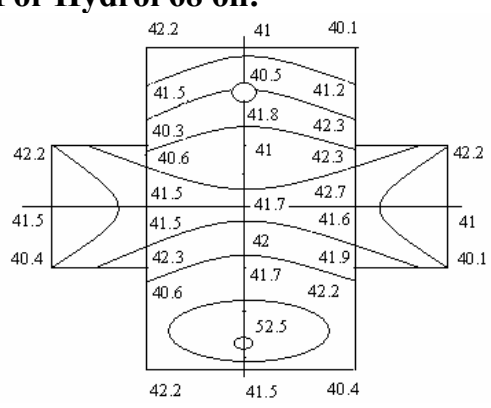

Fig. 5 Temperature distribution $\left({ }^{\circ} \mathrm{C}\right)$ in offset-halves journal bearing at $3000 \mathrm{rpm}, 100 \mathrm{~N}$, ofr $=7.0 \mathrm{lt} / \mathrm{min}$.

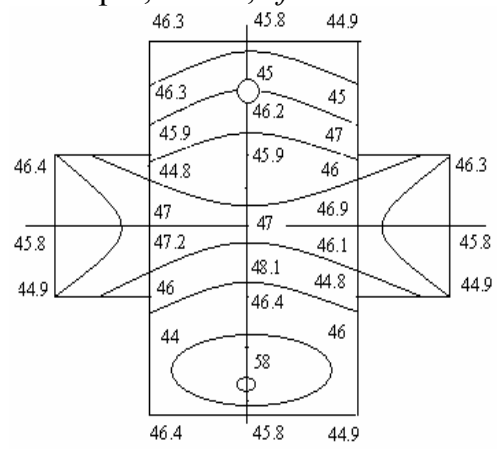

Fig. 8 Temperature distribution $\left({ }^{\circ} \mathrm{C}\right)$ in offset-halves journal bearing at $4000 \mathrm{rpm}, 600 \mathrm{~N}$, of $r=9.0 \mathrm{lt} / \mathrm{min}$

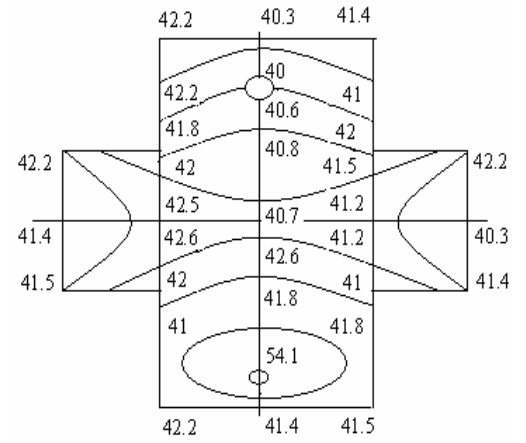

Fig. 11 Temperature distribution $\left({ }^{\circ} \mathrm{C}\right)$ in offset-halves journal bearing at $4000 \mathrm{rpm}, 100 \mathrm{~N}$, of $r=7.8 \mathrm{lt} / \mathrm{min}$

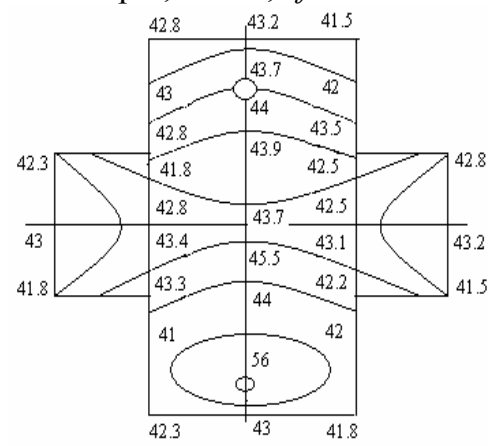

Fig. 14 Temperature distribution $\left({ }^{\circ} \mathrm{C}\right)$ in offset-halves journal bearing at $3000 \mathrm{rpm}, 600 \mathrm{~N}$, ofr $=9.8 \mathrm{lt} / \mathrm{min}$

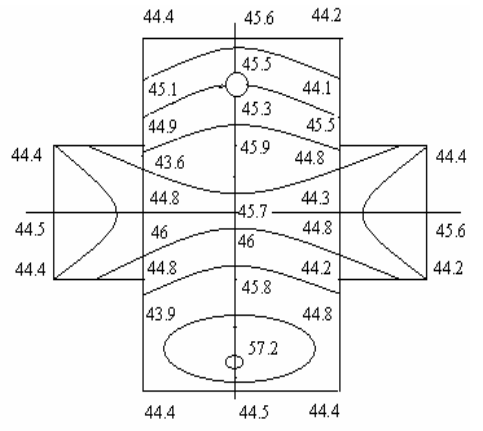

Fig. 6 Temperature distribution $\left({ }^{\circ} \mathrm{C}\right)$ in offset-halves journal bearing at $3000 \mathrm{rpm}, 600 \mathrm{~N}$, of $r=8.6 \mathrm{lt} / \mathrm{min}$.

\section{For Mak 2T oil:}

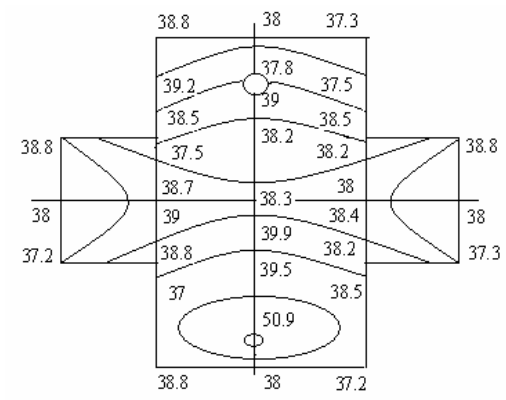

Fig. 9 Temperature distribution $\left({ }^{\circ} \mathrm{C}\right)$ in offset-halves journal bearing at $3000 \mathrm{rpm}, 100 \mathrm{~N}$, of $r=7.7 \mathrm{lt} / \mathrm{min}$

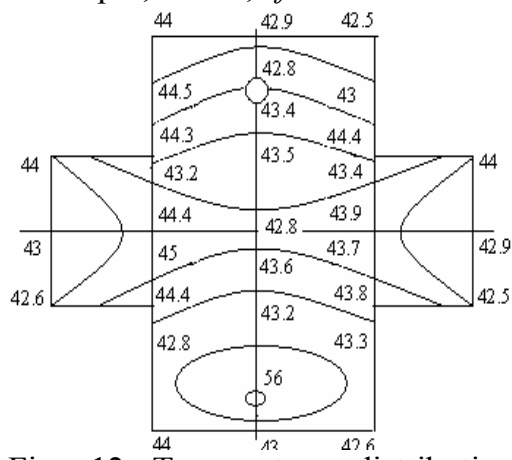

Fig. 12 Temperature distribution $\left({ }^{\circ} \mathrm{C}\right)$ in offset-halves journal bearing at $4000 \mathrm{rpm}, 600 \mathrm{~N}$, of $r=9.0 \mathrm{lt} / \mathrm{min}$

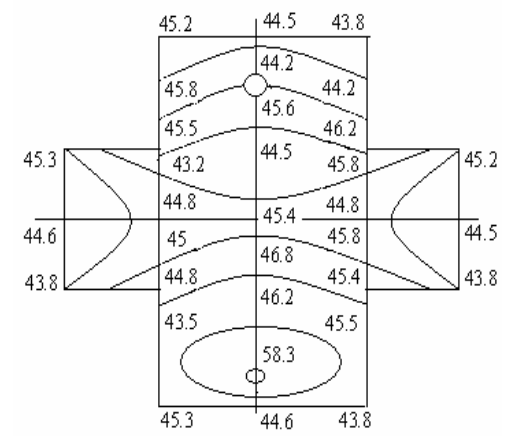

Fig. 15 Temperature distribution $\left({ }^{\circ} \mathrm{C}\right)$ in offset-halves journal bearing at $4000 \mathrm{rpm}, 100 \mathrm{~N}$, ofr $=10.3 \mathrm{lt} / \mathrm{min}$

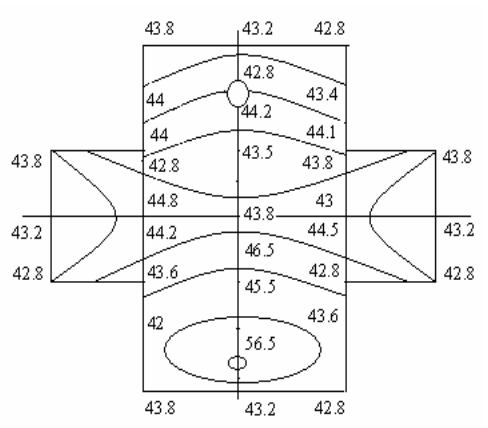

Fig. 7 Temperature distribution $\left({ }^{\circ} \mathrm{C}\right)$ in offset-halves journal bearing at $4000 \mathrm{rpm}, 100 \mathrm{~N}$, of $r=7.6 \mathrm{lt} / \mathrm{min}$

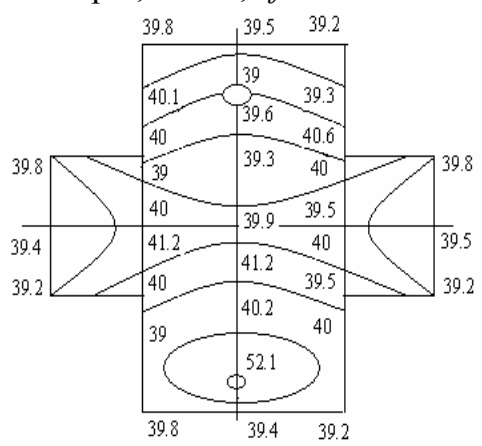

Fig. 10 Temperature distribution $\left({ }^{\circ} \mathrm{C}\right)$ in offset-halves journal bearing at $3000 \mathrm{rpm}, 600 \mathrm{~N}$, of $=9.0 \mathrm{lt} / \mathrm{min}$ For Mak Multigrade oil:

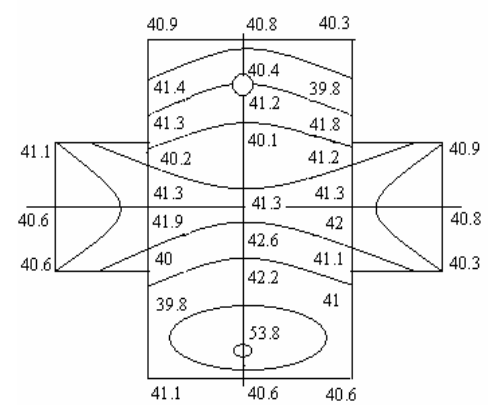

Fig. 13 Temperature distribution $\left({ }^{\circ} \mathrm{C}\right)$ in offset-halves journal bearing at $3000 \mathrm{rpm}, 100 \mathrm{~N}$, of $=9.2 \mathrm{lt} / \mathrm{min}$

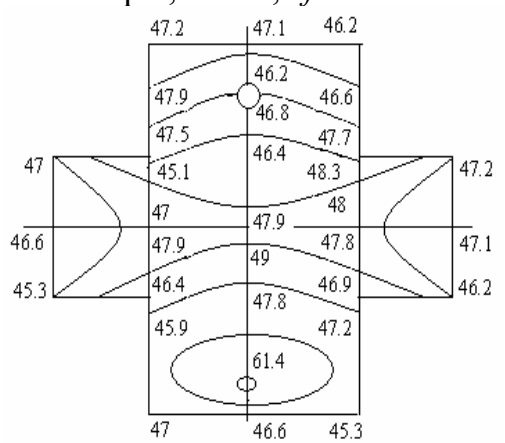

Fig. 16 Temperature distribution $\left({ }^{\circ} \mathrm{C}\right)$ in offset-halves journal bearing at $4000 \mathrm{rpm}, 600 \mathrm{~N}$, ofr $=11.3 \mathrm{lt} / \mathrm{min}$ however, is far low in comparison to temperature rise obtained in lower lobe. However, temperature rise is also observed at another point in diverging zone of lower lobe which possibly can be attributed to mixing of 
hot recirculating oil with comparatively cold input oil at that point. This may also be due to change in resistance of temperature sensor near that point. For lower lobe, maximum temperature rise in central plane of the bearing is observed as $31.4^{\circ} \mathrm{C}$ for Mak Multigrade oil at $4000 \mathrm{rpm}$ and $600 \mathrm{~N}$ (Fig. 16) and minimum temperature rise is observed as $20.9^{\circ} \mathrm{C}$ for Mak $2 \mathrm{~T}$ oil at $3000 \mathrm{rpm}$ and $100 \mathrm{~N}$ (Fig. 9). For upper lobe, maximum temperature rise in central plane of the bearing is found to be $16.8^{\circ} \mathrm{C}$ for Mak Multigrade oil at $4000 \mathrm{rpm}$ and $600 \mathrm{~N}$ and minimum temperature rise is found to be $9^{\circ} \mathrm{C}$ for Mak 2T oil at $3000 \mathrm{rpm}$ and $100 \mathrm{~N}$.

4. It is observed from Fig. 4 that there is sharp decrease in viscosity for Mak Multigrade oil with increase in temperature. Because of this, pressure and hence load carrying capacity of the bearing is expected to decrease. At oil inlet temperature $\left(30^{\circ} \mathrm{C}\right)$, the viscosity of Mak Multigrade, Hydrol 68 and Mak 2T oil is $216 \mathrm{cP}, 76 \mathrm{cP}$ and $66 \mathrm{cP}$ respectively. At maximum temperature $\left(61.4^{\circ} \mathrm{C}\right)$, the viscosity of Mak Multigrade, Hydrol 68 and Mak 2T oil is $25 \mathrm{cP}, 22 \mathrm{cP}$ and $18 \mathrm{cP}$ respectively. Flow rate is lowest for Hydrol 68 oil $(7.0$ lt $/ \mathrm{min}$ at 3000 $\mathrm{rpm}$ and $100 \mathrm{~N}$ ) and maximum for Mak Multigrade oil $(11.3 \mathrm{lt} / \mathrm{min}$ at $4000 \mathrm{rpm}$ and $600 \mathrm{~N})$. Flow rate for Mak Multigrade oil is large at high speeds and loads as its viscosity decreases sharply with temperature in comparison to the other oils considered.

\section{Conclusions}

Journal bearing setup/test rig has been developed to investigate thermal behaviour of non-circular journal bearings experimentally. An offset-halves journal bearing was tested and temperature distributions at circumferential planes were obtained for a series of operating conditions using three oils (supply pressure kept constant). Following conclusions are drawn from this study:

The thermal behaviour of offset halves bearing is affected significantly by rotational speed, loads and type of the oil used. Flow rate increases markedly with speed and load. For lower lobe, maximum temperature rise in central plane of the bearing is $31.4^{\circ} \mathrm{C}$ for Mak Multigrade oil at $4000 \mathrm{rpm}$ and $600 \mathrm{~N}$ and minimum temperature rise is $20.9^{\circ} \mathrm{C}$ for Mak $2 \mathrm{~T}$ oil at $3000 \mathrm{rpm}$ and $100 \mathrm{~N}$. For upper lobe, maximum temperature rise in central plane of the bearing is $16.8^{\circ} \mathrm{C}$ for Mak Multigrade oil at $4000 \mathrm{rpm}$ and $600 \mathrm{~N}$ and minimum temperature rise is $9^{\circ} \mathrm{C}$ for Mak $2 \mathrm{~T}$ oil at $3000 \mathrm{rpm}$ and $100 \mathrm{~N}$. Across the width of bearing, temperature is high at centre of the bearing for all oils. Temperature rise is maximum $\left(17.9^{\circ} \mathrm{C}\right)$ for Mak Multigrade oil at $4000 \mathrm{rpm}$, $600 \mathrm{~N}$ and is minimum $\left(8.3^{\circ} \mathrm{C}\right)$ for Mak $2 \mathrm{~T}$ oil at 3000 rpm, 100 N. For Mak Multigrade oil, there is sharp decrease in viscosity with increase in temperature and as a result of this, pressure and hence the load carrying capacity of the bearing is expected to decrease. It is, therefore, not necessary to use highly viscous oil in such bearings as it may result in high temperature in bearing because of viscous rubbing between oil layers. Therefore, under chosen operating conditions (load up to $600 \mathrm{~N}$ and speed up to $4000 \mathrm{rpm}$ ) and the oils, it is more appropriate to use Mak 2T oil as bearing will run coolest, thus providing desired operational accuracies.

\section{Acknowledgements}

Present work is supported by Ministry of Human Resource and Development, Govt. of India under a Thrust Area Project. The authors gratefully acknowledge the help rendered by M/s DUCOM, Bangalore, India in fabricating the test rig.

\section{Nomenclature}

ID Inner diameter of the bearing

$O D \quad$ Outer diameter of the bearing

$L \quad$ Length of the bearing

$O_{U} \quad$ Upper lobe centre

$O_{L} \quad$ Lower lobe centre

$O_{j} \quad$ Journal centre

$O_{B} \quad$ Bearing centre

$C \quad$ Radial clearance

$\mathrm{Cm}$ Minimum clearance when journal centre is coincident with geometric centre of bearing

ofr Oil flow rate

$e \quad$ Eccentricity

$\varphi \quad$ Attitude angle

$\theta \quad$ Angle measured from the horizontal split axis in the direction of rotation

RTD Resistance temperature detector

\section{References}

[1] Hopf, G. and Schuler, D., "Investigations on Large Turbine Bearings Working under Transitional Conditions between Laminar and Turbulent Flow," Transactions of ASME J. Tribology, 111, 1989, 628-634.

[2] Read, L. J. and Flack, R. D., "Temperature, Pressure and Film Thickness Measurements for an Offset Half Bearing," Wear, 117, 2, 1987, 197-210.

[3] Fitzgerald, M. K. and Neal, P. B., "Temperature Distributions and Heat Transfer in Journal Bearings," Transactions of ASME J. Tribology, 114, 1992, 122-130.

[4] Basri, S. B. and Gethin, D. T., "An Experimental Investigation into Thermal Behaviour of a Three-lobe Profile Bore Bearings," Transactions of ASME J. Tribology, 115, 1993, 152-159.

[5] Ma, M. T. and Taylor, C. M., "An Experimental Investigation of Thermal Effects in Circular and Elliptical Plain Journal Bearings," Tribology International, 29, 1, 1996, 19-26.

[6] Sehgal, R., Swamy, K. N. S., Athre, K. and Biswas, S., "A Comparative Study of the Thermal Behaviour of Circular and Non-circular Journal 
Bearings," Lubrication Science, 12, 4, 2000, 329-344.

[7] Syverud, T., "Experimental Investigation of the Temperature Fade in the Cavitation Zone of Full Journal Bearings," Tribology International, 34, 12, 2001, 859-870.
[8] Mishra, P. C., Pandey, R. K. and Athre, K., "Temperature Profile of an Elliptic Bore Journal Bearing," Tribology International, 40, 3, 2007, 453-458. 